\title{
Derecho a la educación superior en Latinoamérica y migraciones hacia las universidades estatales argentinas
}

\author{
Right to higher education in Latin America and \\ migration to Argentina, state universities
}

\section{Direito à educação superior na América Latina e migrações para universidades estatais argentinas}

\author{
Sandra María Gómez \\ Magister en Tecnología Educativa \\ Universidad Nacional de Córdoba \\ sgomezvinuales@gmail.com
}

\section{Resumen}

En el presente artículo se comparten algunos análisis relativos a una investigación que se viene desarrollando desde el año 2018, sobre las experiencias de los jóvenes que han migrado de países latinoamericanos hacia Argentina para iniciar una carrera de grado en la Universidad Nacional de Córdoba (UNC).

En esta oportunidad se tematizan aspectos referidos al derecho a la educación superior en países latinoamericanos como Chile, Perú y Colombia y las diferencias en las políticas estatales para la cobertura de dicho derecho. Segundo, la relación entre educación superior y los movimientos migratorios que ello acarrea.

Si bien, nuestra investigación hace foco en las experiencias de los estudiantes migrantes, no puede dejar de articularse con las condiciones objetivas estructurales vinculadas a las políticas educativas y migratorias que, en la actualidad, hacen que los jóvenes decidan migrar a países de la región para poder hacer sus estudios universitarios.

Interesa conocer aspectos de los procesos de inclusión de los migrantes en el nuevo espacio social y, para ello, en la investigación se ha optado por un enfoque cualitativo, entrevistando de modo individual y grupal a jóvenes extranjeros matriculados en la Facultad de Filosofía y Humanidades. Las interpretaciones han permitido reconocer experiencias en el país de acogida, distintos itinerarios en la nueva ciudad y en la universidad, transformaciones subjetivas y sociales que el proceso migratorio 
ha generado en estos jóvenes.

Palabras claves: Universidad, jóvenes, migraciones, derecho a la educación.

\section{Summary}

This article shares some analyzes related to an investigation that has been carried out since 2018, on the experiences of young people who have migrated from Latin American countries to Argentina to start a degree career at the National University of Córdoba (UNC).

On this occasion, aspects related to the right to higher education in Latin American countries such as Chile, Peru and Colombia and the differences in state policies for the coverage of said right are discussed. Second, the relationship between higher education and the migratory movements that this entails.

Although our research focuses on the experiences of migrant students, it cannot fail to be articulated with the objective structural conditions linked to educational and migration policies that, at present, make young people decide to migrate to countries in the region to to be able to do their university studies.

It is interesting to know aspects of the processes of inclusion of migrants in the new social space and, for this, the research has opted for a qualitative approach, interviewing individually and in groups young foreigners enrolled in the Faculty of Philosophy and Humanities. The interpretations have made it possible to recognize experiences in the host country, different itineraries in the new city and in the university, subjective and social transformations that the migratory process has generated in these young people.

Keywords: University, youth, migration, right to education.

\section{Resumo}

Esse artigo apresenta algumas análises oriundos de uma pesquisa que vem se desenvolvendo desde o ano 2018 sobre as experiências dos jovens que têm migrado de países latino-americanos para a Argentina, para iniciar os estudos de graduação na Universidade Nacional de Córdoba (UNC).

Tematizam-se aspectos referidos ao direito à educação superior em países latino-americanos como Chile, Peru e Colômbia e as diferenças nas políticas estatais para a cobertura desse direito. Posteriormente, aprofunda-se na relação entre a educação superior e os movimentos migratórios atrelados.

Deste modo, bem que a pesquisa foca nas experiências dos estudantes migrantes, não pode deixar de se articular com as condições objetivas estruturais vinculadas com as políticas educativas e migratórias que, na atualidade, fazem que os jovens decidam migrarem a países da região procurando estudar na universidade.

Portanto, interessa conhecer os aspectos dos processos de inclusão dos migrantes no novo espaço social e, para isso, na pesquisa tem se optado pelo enfoque qualitativo, fazendo entrevistas individuais e grupais a jovens estrangeiros matriculados na Faculdade de Filosofia e Humanidades. As interpretações 
Derecho a la educación superior en Latinoaméricay migraciones hacia las universidades estatales argentinas

têm permitido reconhecer as experiências no país de acolhida, os itinerários na nova cidade e na universidade, as transformações subjetivas e sociais que o processo migratório tem gerado nesses jovens.

Palavras-chave: Universidade, jovens, migrações, direito à educação.

\section{Introducción}

Este trabajo se enmarca en la inquietud de abordar las migraciones académicas que se generan con la intención de hacer una carrera universitaria de grado, por lo que interesa ver los movimientos que se producen hacia Argentina como país receptor, en tanto sus políticas educativas universitarias y sus políticas migratorias son favorables para que los jóvenes provenientes, mayoritariamente de Chile, Perú y Colombia, decidan migrar para estudiar.

Esto requiere de un abordaje en diversos niveles analíticos para poder comprender los procesos. Por un lado, las políticas educativas y las políticas migratorias, en un registro histórico, que permita reconocer rasgos de las movilidades al interior de la región, en función de marcos regulatorios y de las transformaciones educativas en el nivel superior universitario, en clave regional.

A su vez, a una escala menor, la pregunta central apunta a conocer cómo se articulan los proyectos migratorios con los proyectos educativos. Se ha puesto el acento en describir e interpretar las experiencias vividas por los estudiantes desde la migración y los sentidos otorgados a dichas experiencias, a los fines de analizar los itinerarios reconstruidos por los estudiantes con relación al proceso migratorio y al proceso de integración al nuevo espacio social. Desde el enfoque cualitativo, se han realizado entrevistas individuales y grupales a ocho jóvenes, con el fin de recuperar relatos de vida, los cuales permiten profundizar, en una dimensión diacrónica, los procesos migratorios.

El estudio cualitativo que se viene desarrollando desde 2018 se enfoca en las trasformaciones, por efecto de las migraciones, que viven los jóvenes latinoamericanos oriundos de Chile, Perú y Colombia, quienes vienen a estudiar a la Facultad de Filosofía y Humanidades, en la Universidad Nacional de Córdoba. Esta movilidad se genera como consecuencia, al menos en parte, de las políticas educativas de los distintos estados nacionales y las desigualdades sociales, demográficas, económicas y culturales.

Bertaux (1997) recupera la estructura diacrónica, en los relatos de vida, considerando tres órdenes de realidad: la realidad histórico-empírica, la realidad psíquica semántica aquello que refiere a lo que el sujeto sabe y piensa; y la realidad discursiva del relato mismo que refiere a lo que el sujeto quiere decir con lo que él dice y piensa. De esta manera, esta estrategia de investigación se torna coherente con los objetivos, en tanto permite responder al entramado de significaciones a partir de considerar un sujeto en todas sus dimensiones subjetiva, social, cognoscente. En este sentido los relatos proporcionan datos necesarios para el análisis interpretativo de los procesos migratorios y los sentidos que los estudiantes otorgan a los mismos. El análisis de éstos se hace a partir de tres grandes dimensiones: espacial, temporal, vincular; permitiendo interpretar la información considerando la vida en la ciudad, las modificaciones en la vida cotidiana, las nuevas formas de acción y los sentimientos desencadenados por la migración.

En la primera parte del escrito se trabajará el derecho a la educación y los procesos migratorios en nuestra región, como aspectos estructurales que permiten pensar los movimientos intrarregionales.

Luego se enfocará en algunos resultados del proceso de investigación que dacuenta de las 
formas singulares en que los jóvenes viven y significan las experiencias como migrantes $\mathrm{y}$ como estudiantes en la universidad.

En síntesis, se busca comprender estos procesos desde una mirada relacional y diacrónica, para abordar las transformaciones en la vida cotidiana, producto de la migración y los modos en que los estudiantes van elaborando dichas transformaciones, así como los recursos a los que apelan para sostener el proyecto universitario.

\section{Primera parte}

\section{a. Estado, políticas migrato-rias y educación superior}

Rodríguez Vignoli (2008), en su estudio sobre migración interna en América Latina, expresa que los movimientos migratorios se dan por la unión e inicio de la reproducción, por el ingreso a la universidad o la incorporación al mercado. Para el autor "las decisiones educativas llevan traslados de residencia toda vez que no hay opciones de formación escolar o universitaria en el lugar de origen, o éstas no son compatibles con los intereses, presupuestos o antecedentes académicos de la persona" (p.10).

Las causas por las que las personas deciden migrar son múltiples. Este estudio trata de migraciones voluntarias. Entre los principales motivos que generan una migración se encuentran las diferencias de ingreso en la región, las políticas laborales, las políticas migratorias, el éxodo de profesionales, la migración de jóvenes para iniciar o fortalecer sus estudios superiores, entre otras.

¿Cómo ha recibido Argentina los inmigrantes?

Desde finales del siglo XIX y primeras décadas del siglo XX las migraciones intercontinentales fueron parte de la conformación del Estado-Nación. En esos tiempos la necesidad estaba vinculada a la necesidad de poblar el territorio. Tal como firma Moloco (2016):

Hacia fines del siglo XIX, -el Estado-nación ya organizado y pacificado- Argentina se constituye en uno de los principales receptores de la inmigración de ultramar debido a que el gobierno oligárquico liberal formuló y promovió un desarrollo capitalista dependiente basado en la afluencia de capital y mano de obra extranjeras. (p.205)

Entre los años 1880 y 1910 las preocupaciones eran de diversa índole, ocupando el papel de los flujos migratorios un lugar central. La cuestión migratoria fue una pieza fundacional en el proyecto de las élites progresistas de la época. Este proyecto ya se había forjado desde los inicios de la época independentista, pero logró su realización entre fines del 1800 y principios del 1900.

Para 1885, en Argentina, la mitad de los habitantes de la ciudad de Buenos Aires eran extranjeros. Ante esta situación demográfica, el Estado asumió un papel integrador y nacionalizador (Terán, 2008).

La fuerte presencia de inmigrantes europeos generó una representación de una población imaginariamente blanca, como consecuencia de estas olas migratorias. Argentina, como país receptor, propulsó y acogió amplios contingentes europeos que constituirán para estos tiempos la gran masa de inmigrantes.

El pico de extranjeros se registró entre 1890 y 1914, representando casi el $30 \%$ del total de la población. Estas cifras comienzan a mermar una vez culminada la Segunda guerra mundial.

En simultáneo se daban migraciones intrarregionales, pero a muy baja escala. Hasta la década del 1960, el flujo era principalmente entre países limítrofes, motivamos centralmente 
Derecho a la educación superior en Latinoaméricay migraciones hacia las universidades estatales argentinas

en oportunidades laborales emergentes de las economías regionales fronterizas.

Las políticas migratorias, entre 1976 y 2010, tuvieron transformaciones. En los años 90, el efecto favorable de la economía cambiaria aumentó la llegada de peruanos, principalmente.

Estos últimos años Argentina ha sido un país convocante, desde distintos aspectos. Se ha agregado dentro de los móviles más generales, como pudo ser en otros momentos prevalecientemente la salida laboral, la posibilidad de estudiar.

Según Domenech (2009), "en la Argentina las migraciones internacionales han sido constitutivas de los proyectos políticos del Estado" (p. 23). De este modo, según hayan sido los contextos, las inmigraciones fueron vistas como problema, como amenaza o como aporte.

Históricamente, hubo una ambivalencia entre el mito del crisol de razas y la composición de ciudadanía y la exclusión de poblaciones originarias. En este sentido este país siempre se presentó como un espacio incluyente en lo que respecta a la llegada de los extranjeros. Esta aceptación no fue la misma cuando el origen era europeo a cuando el origen era la región latinoamericana.

En América Latina las naciones se pueden agrupar en dos: las que tienen fuerte presencia de población indígena (Bolivia, Perú, Ecuador, Colombia) y aquellos en que la población originaria no ha tenido tanto peso demográfico y cultural. Argentina pertenece a este último grupo. En esta nación prevaleció la idea de regenerar la población, civilizar el estado de barbarie, procesos asociados a modelos europeos o norteamericanos. Esto trajo aparejado la negación de las diversas culturas. Según Tedesco (2012) "las propuestas de escolarización universal, enmarcadas en el pro-yecto de homogeneización cultural, no tuvieron capacidad para incluir a los pueblos originarios y culturalmente diversos" (p. 37). Este desafío hoy persiste y atañe a todos los niveles del sistema educativo. Después del año 55 culmina la inmigración europea y tiene mayor crecimiento la latinoamericana. El Censo Nacional de Población, Hogares y Viviendas 2001 nos permite dimensionar en porcentajes la diferencias entre las inmigraciones intercontinentales e intracontinentales.

\section{Tabla 1.}

Comparación histórica de la población extranjera

\begin{tabular}{lcc}
\hline \multicolumn{1}{c}{ Año } & 1947 & 2001 \\
\hline Población Total Extranjera & 1.435 .927 & 1.531 .940 \\
Población europea & $63.1 \%$ & $22.9 \%$ \\
Población latinoamericana de países limítrofes & $12,9 \%$ & $60,3 \%$ \\
\hline
\end{tabular}

Nota. Fuente: Censo Nacional de Población, Hogares y Viviendas, 2001.

\section{b. El derecho de la educación superior en la región}

Se describe a América Latina como una región fragmentada. Fernández Lamarra y Costa De Paula (2011) caracterizan a los sistemas de Educación Superior en América Latina, con diferencias significativas tanto en sus dimensiones como en la conformación de las poblaciones estudiantiles, en las formas de acceso a las instituciones, en la cantidad y distribución de lo público y lo privado. En todos los casos los distintos sistemas "enfrentan la tendencia universal del exponencial crecimiento en la matrícula, y de los concomitantes problemas de abandono, deserción, fracaso y bajo rendimiento académico" (p.1).

En concordancia con esta expansión Marcela Mollis (2006) destaca el papel de los mercados 
reconfigurando el panorama de la educación superior latinoamericana en lo que la autora denomina un corrimiento desde las universidades reformistas a las instituciones reformadas, corrimiento que ha sido efecto de una presencia creciente de la inversión privada en la oferta de educación superior. En este sentido destaca la necesidad de que la universidad conserve el lugar de producción de los conocimientos técnicos y científicos necesarios para el desarrollo de los países - los cuales no deben estar orientados por el lucro- con un objetivo trascendental que es el de una construcción democrática, justa y equitativa.

En una misma dirección Rama (2007) habla de tres reformas para la educación superior en América Latina y el Caribe, la primera vinculada al movimiento reformista de 1918 en defensa de la autonomía y el cogobierno, la segunda fue la de la mercantilización y la diferenciación que fue mostrando fuertes mecanismos de exclusión y, la última, que de define como la de masificación e internacionalización.

De Sousa Santos (2006) problematiza el lugar de la universidad en la actualidad y menciona tres crisis, de las cuales se destaca la que denomina crisis institucional ocasionada fundamentalmente por lo que él denomina globalización neoliberal, la cual se apoya en la destrucción sistemática de los proyectos nacionales, proyectos que debería ser "el resultado de un amplio contrato político y social...siendo uno de ellos el contrato educativo y dentro de este el contrato de la universidad como bien público" (p. 52). El autor propone una globalización contrahegemónica por el cual el proyecto político articule las acciones del Estado nacional en un marco global, las universidades, los ciudadanos individual y colectivamente organizados y la búsqueda de alternativas de transnacionalización del capital nacional.

Por otra parte, y desde el punto de vista económico, la región también muestra pobreza creciente y concentración de la riqueza en unas minorías. La distribución de la renta genera francas desigualdades en términos de la cobertura de las necesidades básicas como del acceso a los bienes culturales, generando inequidades e injusticia social. Aun así, en esta mirada regional, para el caso Argentina las políticas educativas que se generaron permitieron mayor acceso e incremento en la tasa de egreso de los sectores menos favorecidos económicamente.

En Argentina, entre los años 2004 y 2013, la proporción de jóvenes de 18 a 30 años graduados, respecto del conjunto de universitarios de este grupo etario, experimentó un leve aumento desde el $15 \%$ en el 2004 hasta el $17 \%$ en el 2013.

Pero no en todos los países de América Latina hubo este crecimiento en el ingreso de sectores tradicionalmente excluidos del acceso a las universidades. En el 2006, Rama (citado en Fernández Lamarra,2010) caracterizaba a Brasil y decía que:

Las estadísticas allí muestran que en las universidades públicas hay un número mayoritario de estudiantes que pertenecen a familias con una renta per cápita relativamente alta y origen social elevado, desplazando así a los estudiantes provenientes de familias de trabajadores y de sectores populares. (p.95)

Didriksson (2018) identifica a México, Perú y Costa Rica como países donde más ha crecido la empresa privada en educación. A su vez, ubica una media del $30 \%$ o $40 \%$ en el acceso social a la educación superior de América Latina y el Caribe, siendo más favorable en Cuba, Uruguay y Argentina.

En Colombia, el sistema de educación superior ha tenido grandes transformaciones. La Ley 30 de 1992 definió a la educación superior como servicio público y no como derecho fundamental, lo que implica un modo de pensar la educación en la política pública.

Mora Cortés (2016) expone la idea sobre la 
mercantilización del conocimiento, la cual conduce indefectiblemente al incremento y consolidación de la oferta privada de los servicios educativos superiores. Sostiene que, en Chile y Colombia, dos de los países de donde son oriundos los jóvenes entrevistados, la mercantilización transforma a la mayoría de los estudiantes potenciales, y a sus familias, en sujetos de crédito, dado que para estudiar asumirán un desuda que les acarreará largo tiempo de vida laboral para poder pagarlo. En este sentido, y analizando el caso de la educación superior en Colombia el autor afirma:

La hipótesis de la educación como factor productivo de igualdad no se comprueba en el caso colombiano, pues las desigualdades vinculadas a la clase social, el género, la pertenencia étnica, la discapacidad, la desigualdad regional y el epistemicidio se manifiestan a lo largo del sistema de educación superior y determinan las posibilidades de acceso, permanencia y logro educativo de los estudiantes. Más aún, el interés gubernamental por masificar la educación terciaria, en el marco de una fuerte restricción presupuestal, ha dado origen a la estructuración de un sistema jerárquico cuyos segmentos son ocupados no por la elección libre de las personas que logran ingresar, sino por las condiciones socioeconómicas, de género o pertenencia étnica que poseen. (p. 45)

Estas inequidades por país se vinculan a las políticas de Estado que en cada caso se van generando en relación con la educación superior. Esto interesa porque nos da contexto acerca de las formas en que opera la estatidad con relación a las políticas educativas, en torno a las decisiones del gobierno, a los intereses y a los derechos y obligaciones.

Desde esta perspectiva, el Estado establece otras relaciones con la sociedad y la economía. En ese marco, bien lo expresa el profesor colombiano Mora Toscano (2005):
La educación se presenta de esta forma como un sector cuya misión principal sería la transmisión de datos e información en pro del crecimiento de la ganancia, de manera que constituya una industria y no un derecho. La educación es entonces una mercancía, la cual puede comprarse y venderse, usarse y desecharse, es un insumo el cual necesita un molde para ajustarse a los objetivos financieros requeridos. El mercado abre espacios rentísticos a cualquier nivel, aun por encima de los derechos sociales. (p.255)

En ese mismo año, Argentina ya estaba encaminada hacia políticas educativas que iban en sentido contrario, porque aun cuando la privatización de la educación no se detuvo, surgieron políticas específicas para ampliar la posibilidad de participación de poblaciones históricamente excluidas de la educación superior. En este proceso se crearon varias Universidades Nacionales como la de Río Negro, la de Chaco Austral, de Moreno, del Oeste (con cabecera en Merlo), de Avellaneda, Arturo Jauretche (con base en Florencio Varela), de José C. Paz, Villa Mercedes (San Luis) y de Tierra del Fuego. Las universidades en el Conurbano también son un claro ejemplo de políticas inclusivas:

Hacia el año 2002 el total de estudiantes de todas las universidades del Conurbano ascendía a 51.182, mientras que las universidades tradicionales contaban con una matrícula de 455.323 estudiantes. Para el año 2008 el total de estudiantes de las universidades tradicionales (desde 1999 a 2008) era de 429.718 mientras que la cantidad total de estudiantes de todas las universidades del Conurbano (desde 1999 a 2008) ascendía a 79.037. (Pérez Rasetti, 2014, p. 30).

El proceso peruano de expansión de la educación superior universitaria se inició en la década del ochenta. Entre 1960 y 1980, la matrícula universitaria pasó de ser de 30.000 a 
255.000 y en el promedio de esos 30 años, el $79 \%$ de la matrícula se concentró en la oferta pública. Sin embargo, no es sino a partir del año 2000 que el crecimiento de la matrícula universitaria despegó. Este explosivo crecimiento no fue un asunto fortuito. Fue una decisión del Estado peruano, cuando en 1996, liberó el mercado educativo. La idea era masificar el ingreso, democratizar y satisfacer las necesidades del mercado. La primera se logró, no así la segunda ya que entre los más pobres (Q1 y Q2) la cobertura alcanzó el 10\%, en el quintil cinco la matrícula fue del $45 \%$ (Cuenca, 2015).

Rodríguez y Montoro (2103) agregan, además, el aspecto de la selectividad. Dicen que en las universidades públicas peruanas postulan entre 48 y 63 personas para que sean admitidas 10. En el sistema privado, postulan entre $13 \mathrm{y}$ 15, ingresando la misma cifra, 10. En una misma línea de análisis, Díaz (2008) destaca que para el año 2005 Perú contaba con una población de un poco más de 3 millones de jóvenes entre 17 y 20 años. Solo 411 mil (un12,7\% del total) postularon para la universidad, de los cuales ingresaron 144 mil. Eso muestra las restricciones en el ingreso.

El caso de Chile se presenta como el ícono de la mercadización de la educación superior. Expresa Brunner (2008):

Hay un mercado de consumidores, particularmente visible en el caso de la enseñanza de pregrado, con amplia libertad de elección por parte de los alumnos que habitualmente pagan por el servicio, ya sea directamente o a través de becas y créditos (con variables grados de subsidio) financiados por el gobierno, por el sistema financiero con aval del Estado o por las propias instituciones. (p.457)

En todos los aspectos dista de las políticas en educación superior argentina. Las universidades chilenas son selectivas y se diferencian unas de otras por sus estructuras de propiedad y gobierno, por la captación de subsidios estatales, su capital reputacional, la calidad de sus actividades que logran transmitir al mercado, las estrategias que persiguen dentro de éste, sus niveles de selectividad académica, las características socioculturales de su cuerpo estudiantil y el poder relativo de sus patrocinadores y stakeholders en la sociedad. (p. 36)

Actualmente, en ese país, hay debates en torno a los marcos normativos y los movimientos estudiantiles se expresan al respecto.

En Argentina, las universidades nacionales son gratuitas y de ingreso directo, salvo algunas carreras, que son las menos. En un Proyecto de Ley de junio de 2006, se debatió en torno a la Ley de Educación Superior (LES) vigente, dando fundamentos sobre la necesidad de un nuevo marco legal para modificar la ley 24521 sancionada en plena hegemonía neoliberal. Dicho documento da lugar a discusiones que van alimentando, al menos en parte, los distintos programas que se generaron luego como apoyo económico y social para garantizar la educación superior como un derecho. En un Documento elaborado por el Consejo Interuniversitario Nacional, luego de varios encuentros en el que se debatía el marco legal, y se expresaba la necesidad de que se

defina claramente la gratuidad de los estudios de grado, estableciendo la equidad cono un principio ético o de justicia en la igualdad. Se interpreta a la equidad como la manifestación del sentido de lo justo. La ley deberá garantizar y hacer efectivo el principio de equidad mediante la asignación de recursos suficientes y la prestación de atenciones especiales a los grupos cultural y socialmente más necesitados. Además, se debe establecer una política universal de becas, que asegure la inclusión y propenda a efectivizar la igualdad y la justicia social (2007, p.8-9). 
En la Conferencia Regional de Educación Superior llevada a cabo en el año 2018, en la Universidad de Córdoba, se dieron debates en distintos ejes. Hubo dos puntos que rescatamos centrales al considerar las políticas públicas y la inclusión de los sujetos migrantes que vienen a estudiar a nuestra ciudad: uno es la gratuidad como responsabilidad indelegable del Estado que garantiza ese derecho; y el otro es el acceso igualitario que amplíe la inclusión social tanto en el ingreso como en la permanencia y el egreso.

Ampliar las oportunidades (...) y garantizar, además, elevados patrones de calidad académica en las (nuevas) universidades y generar políticas focalizadas ya no solo en el ingreso, son en la permanencia y el egreso de las instituciones y su posterior inserción en la estructura ocupacional. (Chiroleu, Suasnábar, Rovelli, p.121)

A nivel regional, y desde una perspectiva integracionista, nuestro continente ha hecho esfuerzos que se han materializado en instancias que han dado algunas directrices en torno a la educación superior. Podemos mencionar el MERCOSUR desde donde se incluyó un área de educación para el debate entre Ministros de Educación de los países miembros. También pueden nombrarse el Espacio Iberoamericano de Conocimiento (EIC), Conferencia Iberoamericana de Educación (2008), el Espacio Común de Enseñanza Superior (UEALC / ALCUE), los proyectos ALFA, ALBAN y ALFA INFOACES, estos últimos en articulación con países de Europa. Además, debemos considerar en esta intención de integración regional, las Conferencias Mundiales y Regionales de Educación Superior (CMES y CRES).

Cabe la pregunta: ¿Cómo pensar la región? En los recientes debates en la CRES 2018, se sentía la presencia latinoamericana y caribeña. Cientos de participantes de todas las latitudes de nuestra región estaban presentes. Ansaldi y Giordano (2016) sostienen que hay que comprender y explicar a América Latina como totalidad. Pero, dice, "totalidad no es igual a homogeneidad ni a generalización abusiva $(\ldots)$ es una realidad compuesta de muchas diversidades" (p.31).

Son muchos los desafíos y preocupaciones, algunos de los cuales ya han sido mencionados con antelación. Se agrega a ellos, el fuerte proceso de privatización, lo que trajo aparejado la introducción de nuevos modelos de gestión, la competencia por la matrícula, la nueva modalidad de contratación de profesores, etc. Esto sucede de la mano con la mercantilización de la educación superior, marcada por la comercialización de propuestas de formación. Un antecedente fue la inclusión de la educación en 1999 en el marco del "Acuerdo General de Comercio de Servicios", por la Organización Mundial de Comercio (OMC). La mayor crítica al planteamiento de la OMC es la convicción de considerar a la educación como un derecho y un bien social. Si uno de los desafíos de la educación superior es sentar las bases de una sociedad más justa e igualitaria, resulta fundamental para ello recuperar la idea de educación como derecho y bien social y no como servicio comercial.

Actualmente, en los países de la región, son cada vez más los aspirantes que logran ingresar a las instituciones universitarias, pero luego, las tasas de retención y graduación que los sistemas universitarios alcanzan siguen siendo muy bajas. Quizás uno de los más importantes -como ya se ha señalado- sea que durante las últimas décadas en América Latina se ha expandido la cobertura en educación superior, pero con altas tasas de deserción y una acentuación de la segmentación de los sistemas.

\section{Segunda parte}

\section{a. Migrar para estudiar en la Universidad Nacional de Córdoba}

Las migraciones implican desplazamientos que hacen los sujetos hacia otra región, en el que permanecerán por un tiempo. Este traslado 
requerirá nuevas formas de acción en la vida cotidiana.

Son un tipo de experiencias de traslado que no sólo son mudanzas- cambios de hogar- sino que dan lugar a la emergencia progresiva de nuevas pertenencias.

El fenómeno migratorio puede producirse por múltiples situaciones y sostenerse por variedad de necesidades. De un modo u otro, las experiencias migratorias son algo más que el hecho de reasentarse y cambiar el lugar en el cual vivir. Hay un proceso previo a la migración que involucra cambios psicosociales que se generan en los procesos de planificación y de concreción del traslado al nuevo lugar.

Migrar para estudiar en la Universidad implica un proceso decisorio en el cual se define qué, cómo, dónde, cuándo, con quiénes. Es una migración voluntaria en el que existe un proceso de preparación que permite ir organizando el proyecto de estudio como el de traslado, movilizado por la búsqueda de nuevos desafíos.

La Universidad Nacional de Córdoba ha sido el destino elegido. Los orígenes de la educación superior en Argentina se remontan al colegio jesuítico creado en 1613, en Córdoba. En 1622 se le otorga a dicho colegio el carácter de universidad. En 1856 la Universidad de Córdoba es nacionalizada. Este hecho ofrece otra perspectiva, tratando de superar el localismo. En 1885 la Ley 1597 (Ley Avellaneda) regulará las dos universidades existentes. Inicia una etapa oligárquica y liberal que se extiende hasta 1918, año en que se produjo la Reforma Universitaria de 1918, en Córdoba. A esta ciudad se la conoce como Córdoba la docta, debido al papel fundamental que tuvo y tiene la universidad en la historia cordobesa (Gibaudant, Luna, 2010) La ciudad es un espacio vivido, espacio urbano relativamente novedoso para los jóvenes que arriban con un proyecto de estudio. La migración trae consigo cambios cualitativos respecto de formas anteriores de vivir y convivir, donde se modifican las maneras de intercambio de bienes materiales y simbólicos. La migración implicará, según Del Acebo Ibañez (1996), un nuevo enraizamiento vital. En los estudiantes este proceso va teniendo variantes. El traslado, el habitar el nuevo lugar, puede ser vivido como una oportunidad que ofrece comparaciones en relación con lo conocido. Se da un descentramiento tanto afectivo como cognoscitivo. El proceso migratorio inicia antes de la partida, cuando es un proyecto imaginado. Comienza su concreción en el momento de la partida, desde el lugar conocido (ya internalizado) hacia un nuevo espacio, en el que el sujeto irá haciendo-se lugar, ubicando-se en la ciudad de acogida.

\section{b. Momentos iniciales de la migración}

En el proceso migratorio el pasaje e ingreso a una nueva nación funge como hecho espacial-social-jurídico, que produce una demarcación entre un momento anterior y uno nuevo, entre una condición de ciudadanía y otra nueva, entre lo conocido y lo novedoso.

Las fronteras territoriales se conciben como un límite topológico que, cuando se ha traspuesto, produce una discontinuidad en relación con el espacio de partida. Las fronteras nacionales son límites topológicos geopolíticos y son, a la vez, límites dotados de significación social. Instauran una partición, separa espacios y los diferencia, denota un límite espacial y social generando un impacto en el sujeto. Lussault (2015) expresa que:

Atravesar la frontera es experimentar explícitamente un cambio de estado en la organización social, que pone de manifiesto la llegada a un país diferente (significado geopolítico y social) o simplemente un espacio social distinto en el seno de un mismo país (significado social). (p.113)

La decisión de trasladarse a Argentina es motivada, aunque no solo por ello, en la 
Derecho a la educación superior en Latinoaméricay migraciones hacia las universidades estatales argentinas

gratuidad y accesibilidad no restricta a la educación universitaria. El cambio de nación obedece, principalmente, a las oportunidades que este país brinda para hacer los estudios superiores. La concepción de educación pública en cada país de los que provienen los jóvenes (Perú, Chile, Colombia) es diferente, estructurando condiciones objetivas de ingreso y permanencia, que limitan las posibilidades efectivas de estudios superiores. La gratuidad es una condición de partida que motiva la migración, pero no es el único factor generador de desplazamiento ya que se combinan otros aspectos personales, familiares, económicos, políticos que tallan en estas decisiones. En ese sentido los jóvenes entrevistados relatan:

JP 5: Yo llego en el 2016 creo, no...2014, (risas) 2014; el 11 de abril, no me olvido más. El 11 de abril ...yo estudiaba Ingeniería industrial y quería seguir mis estudios acá porque mi hermana ya estaba estudiando acá, en la Argentina. Porque yo, allá, estudiaba en una privada y es muy difícil ingresar a las nacionales... Es muy complicado... Se presentan miles y hay cupo para cien y uno que recién salía del secundario, como que no; asi que, bueno, opté por una privada. igual hice el intento y me quedé fuera por un punto, cosa así, que bueno, opté por la privada Con mi mamá vi que me salía lo mismo estudiar en la privada allá, que estudiar en una nacional acá en Argentina, el mismo monto, digamos, cantidad de dinero. Así que decidí venir y estudiar acá. (Entrevista individual 1, 2018, Perú)

JC4: ... la Educación pública fue el motivo por el cual yo estoy en Argentina, que fue el motivo de empezar a trabajar acá (...) $Y$ yo en una familia trabajadora, asi del campo, estando en un conflicto armado, entonces... yo...como que vengo a estudiar, pero me considero más como trabajadora que estudiante, a veces, entonces, en mi condición de inmigrante mujer, trabajadora... (Entrevista individual 1, 2018, Colombia)
En Colombia se agrega la situación particular relativa a los conflictos armados internos que puede ser un factor no menor que coadyuva en la decisión de migrar (Giraldo Quintero, 2017).

Los entrevistados relatan estas experiencias de pasaje, vivencias que van dejando algunas marcas en las formas de ir subjetivando los lugares, en una comparación que van haciendo con su país de origen. Es inevitable ese juego de semejanzas y diferencias como mecanismo subjetivo de elaboración de la novedad en correspondencia con algo de lo conocido. Uno de los jóvenes llega primero a Buenos Aires y luego se traslada a Córdoba. Ese desplazamiento y asentamiento se decide y sostiene por el grado de proximidad entre la ciudad de Córdoba y el espacio de origen.

JC5: P. es como la segunda ciudad más importante de Colombia después de Bogotá...eh...y mi familia es de un pueblo de $P$. que está a unos 50 kilómetros más o menos pero, como yo estudiaba, vivía en P....eh...entonces como que se me hizo mucho más familiar el parecido, más acogedor, qué sé yo, el ritmo y la forma de vida en Córdoba que P., igual a P.; $y$, bueno, decidí quedarme porque Buenos Aires es demasiado grande... (Entrevista grupal1, 2019)

Luego del traspaso material de la frontera se genera un segundo momento que es el arribo al lugar de residencia, el cual puede sufrir algunos cambios hasta la decisión final de permanencia, como es el caso del estudiante citado anteriormente. Asentarse en un lugar es imprescindible ya que en ese espacio comenzará a organizar la vida cotidiana, los estudios, el trabajo, los nuevos vínculos, las actividades.

En una operación semántica los estudiantes comparan los lugares y, con ello, los espacios se connotan otorgando nuevos sentidos y viviéndolos de modo particular, en una serie de reconocimientos que progresivamente se constituirán esquemas de acción, recursos de 
que enriquecen el capital espacial, multiplicando prácticas-espacios de afianzamiento y arraigo.

Estos jóvenes eligieron la ciudad de Córdoba, ciudad que impactará de distinto modo. El clima, el paisaje, las sensaciones y percepciones causan bienestar o malestar, lo que se expresan con distinta intensidad en los relatos de los estudiantes.

Entrevistador: ¿Viniste de Chile a Córdoba? JCh1: Directo, sí. Me vine en bondi. Me acuerdo de que odié a Córdoba, el clima, el calor... Llegué en enero, 27 de enero. Re húmedo. La humedad, me hacía que me doliera los huesos. Estuve mucho tiempo así... (Entrevista grupal 1, 2019)

Otro estudiante dice: JCh2: Me acuerdo de que vinimos en diciembre, vinimos un par de días. Vinimos tres días y ahi conocimos la universidad, conocimos Córdoba y el clima que hace calor (risas) y esa humedad... (Entrevista individual 1, Chile, 2018)

De manera contraria al impacto que el verano genera en las estudiantes chilenas, la llegada en otoño del joven colombiano produce otras sensaciones y da apertura a una vivencia estética, la de una mirada sensible, que se disfruta a partir de la comparación del paisaje que ofrecen las tonalidades de los árboles en la ciudad universitaria, potenciada esta observación por ausencia de estaciones en su país, Colombia. La ciudad en otoño conforma para este sujeto un paisaje, escena, constituida como una representación, valoración tímica traducida en una apreciación de belleza, que reaparece en este joven durante las distintas entrevistas realizadas.

JC5: Uno cuando recién llega y viene de Colombia donde no existen las estaciones propiamente, reconocer que era el otoño, cuando solamente lo había visto, no sé, solamente en películas, en imágenes, como que causa cierta... una imagen como muy muy fuerte, es muy bella (Entrevista individual 1, Colombia, 2018)

El mismo joven en la entrevista individual vuelve aludir a ese impacto paisajístico y relata:

Yo llegué en otoño a Córdoba...eh...era precioso, para mí era poético ver la universidad y ver todo el piso lleno de hojas de todos colores y cuando...en Colombia no existen las estaciones, por ejemplo. Entonces existen lugares de mucho calor o más cálidos, pero por el resto no hay invierno, no hay otoño, las hojas son siempre verdes...entonces, para mí era como sumamente novedoso eso...me parecía, no sé, estar leyendo un libro viejo...eh...o viviendo un libro viejo, entonces eso me impactaba muchísimo... (Entrevista grupal 1, 2019)

Para Greimas, Fontanille (2002) hay una sensibilidad pasional en el discurso, la cual podemos identificar en la modelización narrativa de este estudiante, donde se conjugan el conocer y el sentir.

Hay una operación de discernimiento que implica una disyunción del sujeto con su lugar de origen, efecto de la separación, de ausencia de lo anteriormente conocido, disyunción que genera en el sujeto esta significación del nuevo espacio por negación de lo anterior. Es Córdoba una región en la cual las estaciones presentan una clara variación climática, evidente en los cambios de los paisajes. Eso que no sucede en Colombia, si sucede aquí. El nuevo lugar no es lo que era el anterior. La conjunción del sujeto con el nuevo lugar genera una tensividad emocional que se registra en los efectos pasionales más que racionales, en expresiones más o menos cercanas al placer o al displacer, según sea la situación (Greimas, Fontanille, 2002).

Son Córdoba ciudad y ciudad universitaria, los espacios a los que llegan. Hay una topografía particular en ambos lugares, una disposición 
material que los configura. La ciudad es electa por su tamaño, por la asequibilidad en las dimensiones de esta urbanización. La universidad los sorprende por su apertura. La comparación prevalece en la valoración de lo vivido, jugándose experiencias y evocación de imágenes que dan cuenta de las repercusiones subjetivas de la morfología de estos espacios. La apreciación de las formas y tamaños son elementos significados en los relatos sobre ambos espacios.

JCh1: que cuando era muy chiquita, o sea más chica, mi papá nos trajo a Córdoba. Ehhh o sea fuimos a Brasil de viaje, en un viaje familiar, y pasamos por Córdoba porque fuimos en auto de Chile hasta... no sé Florianópolis creo, y en ese trayecto pasamos por acá. $Y$ siempre como que quedó en mi memoria como... qué se yo, cosas de Córdoba que me gustaron, supongo. Que era como la infraestructura, asi como antigua, que me acordaba mucho que era como una ciudad, pero no tan grande y también, a la vez, como que había campo alrededor. (Entrevista grupal 2, 2019)

Las organizaciones urbanas se diferencian por su tamaño y existen escalas que arrojan una clasificación de estas según medidas objetivas. Lo que interesa ahora es ver la perspectiva subjetiva de los estudiantes en tanto el efecto en su vida cotidiana, dado que ellos suponen que vivir en una ciudad de determinado tamaño ofrecería un espacio urbano con una serie de condiciones que serían formas parecidas a los modos de vida anterior.

Para los jóvenes entrevistados la ciudad de Córdoba, en función de su tamaño (escala), podría ofrecer una vida con ciertas semejanzas a las ciudades de origen. Por otra parte, es un espacio urbano atractivo con una dinámica que se aleja a las formas de las grandes metrópolis, generando un sentimiento de mayor seguridad y cobijo social.
Córdoba es uno de los destinos posibles dentro de otras muchos que existen en este país. Puede ser la ubicación geográfica como provincia mediterránea, pero también su historia. Es una de las universidades más antiguas de Latinoamérica y las más antigua de Argentina. Córdoba tiene el calificativo "La Docta". Dicho adjetivo obedece precisamente a la presencia de esta institución como símbolo de saber y cultura. Ese capital simbólico puede ser uno de los motivos de elección.

Para el caso de los migrantes extranjeros el acceso y la gratuidad son factores explicativos fundamentales en la opción. Entonces nos dicen:

JC5- Porque es mucho más fácil acá que en Colombia el estudio. En Colombia piden muchas calificaciones y las universidades son muy cerradas en si mismas, los cupos y esas cosas. En cambio, acá es mucho más fácil estudiar. (Entrevista individual 2, Colombia, 2018)

JP2- Porque allá la facultad sale muy cara y más dependiendo del sector que vos querés elegir, no sé cómo se dice, es la... disciplina... (Entrevista individual 1, Perú, 2018)

Para los estudiantes, esta ciudad se hace deseable como destino para estudiar. Hay representaciones previas en torno a este espacio urbano, a la vida juvenil, a la variedad de actividades, al prestigio de la Universidad Nacional de Córdoba, siendo los motivos más significativos dentro de los nombrados.

Para ilustrar los itinerarios de llegado hemos elegido dos casos. En cada uno de los jóvenes las experiencias han sido distintas. Entonces si bien, en muchos aspectos se encuentran recurrencias con relación a lo que generan los procesos migratorios, los recorridos realizados y las decisiones tomadas hasta la llegada a destino, son muy variadas en función historias personales y recorridos particulares. 
Un estudiante, quien ya había iniciado estudios superiores en una ciudad noroeste de Colombia en una institución privada, decide venirse a Argentina. Un joven amigo que había estado en Buenos Aires regresa de un proceso de intercambio y le comenta la riqueza de esa experiencia. Esas palabras producen una movilización en Marcos, que articulados con aspectos de la vida personal se combinan para tomar la decisión de migrar hacia Argentina.

Expresa en distintos momentos en las dos primeras entrevistas:

JC5: "Yo me puse la convicción de querer irme". Más adelante dice "pienso, yo tenía toda una vida en $X$ (su ciudad), vivía en el departamento de mi papá, con mis primos, estudiaba en la universidad, estaba en el tercer semestre de la universidad, ehh, como que tenía un proyecto armado y decidi viajar...". Se viene con una idea que él denomina "de aventura" (Entrevista individual 1, Colombia, 2018)

Arriba a Buenos Aires y es alojado por un grupo de compatriotas. Reside hasta mediados de año, no se puede inscribir en la Universidad de Buenos Aires y luego de unos meses decide viajar hacia el interior. Le recomiendan Córdoba. En principio iba a regresar a Buenos Aires, pero encuentra en Córdoba un lugar parecido a la "lógica de su ciudad".

Otro caso es el de Tiziana, joven chilena, que ya ha culminado un estudio de grado en la ciudad de Santiago pero que un momento de su vida decide venirse hacia Argentina. Las palabras de un profesor son significativas en dicha decisión, aunque como en el caso anterior condiciones objetivas y particularidades subjetivas estará tallando en ese cambio. Es egresada de una carrera de comunicación, pero la antropología era su inquietud. Elige entre tres posibles destinos: Misiones, Buenos Aires y Córdoba. Descarta Mendoza por la cercanía con Chile. Había visitado la capital cordobesa en una ocasión, cuando era niña. Se viene con su novio quien inicia la carrera de Letras, pero al poco tiempo deserta y retorna a Chile. Ella decide quedarse. Por un largo tiempo sufre sentimientos ambivalentes. En relación con ello relataba en una de las entrevistas:

JCH1: ... y bueno, y ahí también hay un tema, ¿no? Lo digo por el tema de venirme, yo no soy mucho de andar viajando por el mundo digamos, (rie) no. Eh...y cuando me vine estuve un año, siempre digo, entre Chile y Argentina. Fue como que no sabía por qué estaba acá. O sea, después de estar "super" decidida a que bueno: "yo quiero ser antropóloga y voy a hacer lo que sea para irme y ser antropóloga" eh... había un montón de cosas que me atajaban allá, viste. Me atajaban asi que me decían: "no, no tenés que irte", era como que te ponen, como... viste esas cosas, así como de los presos. ¿cómo se llama? Se me fue el nombre ahora...

Entrevistador: las esposas. JCH1: las esposas, eso mismo. O sea, es como que vos no podés salir del país porque se te aparecen esposas y bueno... desaparecen y aparecen.

Cuando se relata se reconoce como una persona "muy diferente a como era hace seis años atrás". Uno de los motivos de la migración será lo que ella denomina "una insatisfacción profunda... insatisfacción de vivir en torno a lo económico".

Porque "Chile es un pais, digamos, supergringolandia..." (...) no te van a enseñar a "ándate a Argentina que es un país que te va a enseñar un montón de otras cosas, pensamiento crítico, qué sé yo". O sea que tienen un pensamiento más de izquierda, no, eso no. Ellos no quieren. Entonces yo creo que bueno, como le comento a algunos amigos que también salieron, que... yo creo que he pensado que somos... es como que yo me siento 
digamos como migrante, como haber salido de mi país. De haber salido ya con estos cuestionamientos, como que me siento, como que soy. $O$ soy o cai dentro de una grieta de ese proyecto que tiene Chile. Porque en el fondo nadie se pregunta nada. Te lo digo en serio. (Entrevista individual 2, Chile, 2018)

Las primeras experiencias en la ciudad y en la universidad son aquellas que van generando en los sujetos las percepciones y valoraciones del nuevo espacio, por comparación a sus lugares de origen y a experiencias educativas anteriores, en donde la decisión del destino articula decisiones anticipadas y circunstancias que van dando lugar a un progresivo sentimiento de pertenencia y de mayor estabilidad subjetiva y social, sumado a los logros que van alcanzando en la universidad.

\section{c. Andar la ciudad}

Los espacios urbanos se van construyendo progresivamente a partir de experiencias de desplazamientos concretas y de discursos que circulan sobre los lugares urbanos que constituyen y que circunscriben la ciudad.

Los itinerarios de cada uno de los jóvenes han sido condicionados por los lugares de residencia y los recorridos para llegar a la universidad y a puestos de trabajo. Esas necesidades han delimitado en gran parte los itinerarios y los espacios que han ido conociendo y conformando su capital espacial.

En las entrevistas los estudiantes van relatando sus recorridos describiendo espacios materiales, desde experiencias vividas y elementos representacionales que van armando en sus discursos, incidiendo en las formas de apropiación de los lugares urbanos y de sus espacios privados.

$\mathrm{Al}$ inicio de la migración todo espacio es nuevo. El centro de la ciudad ofrece una fisonomía que genera mayor seguridad que los barrios aledaños.
JC5: yo primero vivo en San Martín (barrio relativamente cercano del casco céntrico) un mes y me voy porque me pareció un barrio muy hostil en ese momento. Era recién llegado, no conocía a nadie, estaba cerca de la cárcel de San Martín y se me hacía tan hostil en ese momento, en el que estaba tan solo (...) $\quad \mathrm{Y}$ al mes $\mathrm{y}$ medio yo encuentro este grupo (algunos migrantes) que me invitan y me voy al centro (Entrevista grupal 3, 2019)

Luego de estar entre cuatro y cinco años en Córdoba capital las narraciones coinciden en que se han movido en espacios cercanos al centro y a barrios céntricos, siendo excepcional y bajo alguna circunstancia especial, el que se hayan desplazado más allá de un perímetro cercano a sus viviendas y-o a la universidad.

La fisonomía funciona como un operador espacial que condiciona el uso de los espacios en cuanto a movilidad y a sociabilidad, facilitando o limitando las posibilidades de acción. Luminosidad, comercios, espacios verdes, estética de las viviendas se pone en juego cuando los jóvenes van habitando el nuevo lugar $\mathrm{y}$ van construyendo familiaridad respecto de estos mismos.

JC5: Para mi era como muy hosco porque es un barrio muy oscuro, poco iluminado, solo a esa hora en la noche, era bien adentro, como medio pasaje, y también era eso de no conocer a nadie; era el primer punto de referencia que estaba teniendo cuando llegué a Córdoba, y entonces yo venía en Buenos Aires de vivir San Telmo como un lugar mucho más iluminado (Entrevista grupal 3, 2019)

La cita textual anterior que pertenece a un joven colombiano se suma a otras expresiones de una estudiante también colombiana, en donde, ambos refieren el haber vivido en un país en el cual, en las zonas alejadas, rurales y de montaña, se daba la mayor violencia. Ese registro, aun cuando había conciencia de estar en otro lugar, 
persistía y estaba latente. "Digo por más que esté racionalizado yo tenía por todo el cuerpo este sentir" (JC4, entrevista individual, 2018).

Los estudiantes portan sus historias, oriundos de distintos países, han transitado de modo diferente los espacios urbanos, sin embargo, coincide una sensación de extrañamiento que todos han experimentado cuando han recién han llegado a la ciudad.

Las experiencias en los espacios, al menos las que fueron nombrando, se hallaron circunscriptas a necesidades y a recorridos producidos por mudanzas, cambios de trabajo y ampliación de la vida académica y social. Se suma a ello un discurso instalado en el imaginario social que les fue anticipando lugares más seguros que otros para transitar. Esos enunciados delimitaron los espacios conocidos o susceptibles de ser vividos, enunciados que coartaron o condicionaros los desplazamientos por la ciudad.

JCh1: "Este era el recorrido y mucho tiempo; ni siquiera iba al centro, centro no, no. Me acuerdo de que un chico me dijo no vayas a cruzar de la Cañada, para allá, porque hay mucha cosa mala así. Yo quedé loca porque por un tiempo no crucé la Cañada para allá (risas). Será porque me advertía que me podía pasar algo de inmediato que me podían asaltar o cualquier cosa, viste. Bueno yo decía bueno era como la meta era ahí en la Cañada, no sabes, y ahora vivo en la Cañada "(Entrevista grupal 3, 2019).

Los recorridos de esta joven, durante el primer año y medio, se localizó en ir y volver a la universidad, "de Nueva Córdoba a la universidad y de la universidad a Nueva Córdoba (...) creo que la única parte que más conozco de Córdoba es el centro y el centro (JCh1, entrevista individual, 2018). Es desde ese recorrido diario que va construyendo vínculos sociales, estableciendo una red de amistades con jóvenes que trabajan en comercios a los que asistía diariamente. En este caso, luego se van ampliando los espacios desde actividades académicas que hacen que se multipliquen los lugares. De ese modo participará de actividades en uno de los museos de la ciudad y en el zoológico, en los que estará de manera activa en los últimos dos años.

Para otros jóvenes se amplificarán prácticas sociales, culturales y comerciales en las plazas públicas. La invitación de otros jóvenes a ser parte de nuevas actividades acrecentará el abanico en la vida social. En la Facultad, para algunos de los entrevistados, la militancia se vivirá como una oportunidad para configurar grupo, identificándose con luchas que los harán sentirse parte.

La cercanía a la universidad es una clave en la elección del espacio donde vivir. Los itinerarios cotidianos se hacían caminando, en bicicleta $\mathrm{y}$ con poca regularidad utilizaban transporte público.

Se observa como la organización de las espacialidades se articuló con modalidades de uso, regulados por relaciones de distancias y proximidades socialmente construidas, ordenadas en espacios geográficos.

Adaptarse al nuevo espacio social, reconocer lugares, habituarse a nuevos recorridos, tomar precauciones, superar temores, generar redes sociales, buscar soportes psicosociales, ampliar progresivamente ese nuevo mundo referencial, son aspectos que los jóvenes han ido mencionado como parte del proceso de integración al nuevo espacio social.

\section{Al cierre}

En una escala más amplia, se debe seguir trabajando a nivel nacional y regional en lo relativo a las políticas educativas en el nivel superior, las cuales aboguen por la justicia social y el bienestar. Desde una lectura crítica son muchos los desafíos relativos a la expansión 
mercantil de la educación superior, a la privatización creciente del nivel y la internacionalización concebida como mercado universitario que, como región, se deben seguir abordando. Esto procesos minan el concepto de educación como bien público y social.

De Sousa Santos (2006) sostiene que la universidad pública dejó de ser una prioridad en las políticas públicas de los Estados nacionales como consecuencia del modelo de desarrollo económico neoliberal impuesto desde 1980, dando lugar a la creación de un mercado universitario. Este proceso generó una descapitalización de la universidad y la transnacionalización de ese mercado universitario, profundizando la segmentación del nivel superior y diferenciación centro-periferia en el consumo de los servicios, reproduciéndose el carácter colonial de la universidad. Este autor propone una globalización contrahegemónica que pueda ir revirtiendo este proceso, atendiendo a las transformaciones actuales, pero recuperando aspectos sustantivos vinculados a la autonomía universitaria, en el marco de un proyecto político mayor.

En este mismo sentido, en la Conferencia Regional de Educación celebrada en Córdoba, con ocasión de los 100 años de la Reforma Universitario de 1918, Guarga (2018) aboga por la defensa

del sentido político del ideario reformista, ya que constituyó y constituye un proyecto social, educativo y esencialmente político con una especial perspectiva latinoamericanista. La esencia de la dimensión política de este modelo de universidad no solo tiene su punto de partida al considerar a las universidades como parte de las políticas públicas (educativas, científicas y tecnológicas) sino también al identificar a las universidades en sus capacidades de transformación social, cultural y productiva a partir de la educación y del desarrollo científico y tecnológico. Se identifica además en las universidades un rol ético político en la reproducción social de principios y valores fundamentales. (p.7)

Uno de los puntos centrales que ha sufrido la universidad pública es el desfinanciamiento, el cual se ha producido en simultáneo con una demanda de mayor cobertura educativa. Mora Cortés (2016) considera, para el caso de Colombia, este proceso de masificación y de restricción presupuestal, expansión que no ha significado necesariamente el tránsito hacia un sistema de ingreso irrestricto $\mathrm{y}$ predominantemente público, sino más bien un modelo que "produce y reproduce la exclusión y la desigualdad, se legitima mediante los discursos del mérito individual y la igualdad de oportunidades, naturalizándose por medio de una concepción individualista de los desempeños y las posiciones sociales alcanzadas" (p. 123). Este análisis también vale para los otros países de la región.

En las circunstancias actuales, y en el marco de los debates abiertos en ocasión del Centenario de la Reforma del 18, Rodrígues Días (2018) retoma el tema de la autonomía universitaria y expresa la necesidad de que las universidades deben sostenerse insumisas a los poderes económicos y financieros, solicitando en que en "el centenario de Córdoba se insista en los conceptos básicos que garantizan a la enseñanza superior su estatuto de bien público" (p.40).

En pro de una reforma democrática y emancipadora de la universidad de Sousa Santos (2006) ofrece análisis sustantivos sobre cuáles son los desafíos en los que trabajar para superar los efectos de la globalización neoliberal. Sobre esto se ha hablado en un apartado anterior, enfatizando la gratuidad y el libre acceso como parte de la democratización de la educación superior. El autor expresa que existen todavía factores de discriminación relacionados con la raza, la etnia, la discapacidad y los condicionamientos económicos, culturales, geográficos. De este modo se puede decir que no alcanza solo con ingresar a la universidad, es 
indispensable una batería de estrategias e intervenciones para que los estudiantes se sostengan de la mejor manera en los estudios, evitando lo que Ezcurra (2011) denomina "puerta giratoria", proceso de inclusión excluyente. Para la autora, en América Latina es necesario abordar las diferencias en los puntos de partida ya que la correspondencia entre nivel educativo de los padres y la graduación denuncia una desigualdad social profunda y rotunda. En el caso de Argentina se evidencia en aquellos jóvenes que, en sus familias, son primera generación que accede a la universidad.

Esta situación se articula con la necesidad de que la universidad sea permeable a las demandas sociales, que asuma, en palabras de Sousa Santos (2006) "una respuesta entusiasta y creativa frente a los desafíos de la responsabilidad socia... desafíos que son contextuales en unción con la región" (p.79) La globalización contrahegemónica que propugna el autor invita a que haya articulaciones nacionales y globales basadas en la reciprocidad y beneficio mutuo pensando un internacionalismo de larga duración que rompa la lógica mercantilista de la universidad.

En una escala menor, tal como se había anunciado en la introducción del escrito, cabe conocer el modo en que estas condiciones estructurales generan procesos que se encarnan en sujetos concretos. La investigación ha abordado las formas singulares en que los jóvenes migrantes viven y significan las experiencias en el nuevo lugar y en la universidad, pretendiendo captar efectos de los procesos más globales, característicos y contextuales de las políticas públicas, en lo relativo a la migración y a la educación superior.

Se ha visto que la migración entraña aspectos ambivalentes, la necesidad de independizarse y el disfrute por la posible autonomía. Extrañan y a su vez conquistan el espacio propio. Como experiencia de desplazamiento, es un movimiento objetivo de traslado de un lugar a otro que genera movilizaciones subjetivas. Dicha experiencia coloca al sujeto en situaciones contradictorias, en las cuales se siente nostalgia por lo anterior conocido, pero a su vez, despliega oportunidades concretas de realización personal en el marco de un desapego constructivo respecto del espacio parental. Asimismo, hay que destacar la contracara de esta experiencia diaspórica que arrastra un desgarre, la pérdida de objetos investidos libidinalmente y situaciones conocidas que dan el marco de seguridad a las acciones cotidianas.

Los jóvenes, cuando llegan al nuevo país, vienen a estudiar con la una idea inicial de probable retorno. A medida que pasa el tiempo aparece un sentimiento de "provisionalidad duradera" que se da entre dos espacios, el de origen y el actual. Sayad (2010) cuando estudia la emigración de los jóvenes de Argelia hacia Francia exalta esta idea y agrega, además, siguiendo las interpretaciones anteriores, que el uso del tiempo, las actividades, el ocio, la vestimenta, etc., han cambiado. Ya los sujetos no se ajustan, antes naturalizado, a las formas de hacer que antes eran habituales.

La experiencia universitaria y la experiencia migratoria les ha expandido el mundo objetivo, social y cultural; y el mundo de la vida -constituido por sistemas culturales de interpretación- se tensiona con las situaciones emergidas desde la migración. Ello origina tematizaciones, en un proceso des-centrador, en los que algunos aspectos del mundo subjetivo y social se visibilizan por contraste a lo conocido, dando lugar a nuevas construcciones (Habermas, 1999).

El impacto de estas vivencias los lleva a la comparación con lo dejado. Van tomando el gusto por la vida en la nueva ciudad. Los jóvenes confrontan maneras urbanas de ver, de actuar, de vivir, de consumir, diferentes en muchos aspectos a las de su lugar de origen.

Los cambios vividos supusieron pérdidas 
Derecho a la educación superior en Latinoaméricay migraciones hacia las universidades estatales argentinas

que requirieron de tramitaciones psíquicas que permitieron, en los ocho casos, un proceso de ajuste y de construcción de su lugar en el nuevo espacio social. Ese proceso des-centrador les ha permitido enriquecer su capital cultural y social a lo que se suma la conquista de autonomía. Otra habitualidad en la cual puede decidir sobre tiempos, espacios, vínculos, prácticas. En el proceso de inclusión se han ido dando transformaciones, en una incorporación significativa de lo novedoso, generando nuevas disposiciones sociales y elaboraciones subjetivas. Lo mismo ha sucedido con las experiencias en la universidad.

En la investigación se sigue trabajando la construcción del espacio social, las redes sociales, el espacio universitario, los espacios de contención en la universidad y en la ciudad, los agrupamientos, el futuro, entre otras cuestiones.

Se desea poder colaborar en un proceso de desnaturalización de las migraciones producidas con el fin de estudiar en la universidad. Siguiendo a Wright Mills (2003) el problema se puede pensar a partir de operaciones como la imaginación sociológica, la cual procura una lectura que articula las inquietudes humanas y los problemas públicos de la estructura social, considerando los aspectos culturales y políticos de las ciencias sociales.

Los nuevos resultados de la presente investigación podrían aportar a la comprensión de estos procesos, dando lugar a intervenciones probables que colaboren con el bienestar del estudiante, y la concomitante inclusión. La visibilización de los pormenores de estos procesos generaría aportes para pensar formas de acompañamiento que se puedan desplegar desde la Universidad como vía de ayuda en la consecución del proyecto de carrera universitaria, favoreciendo situaciones de mayor bienestar subjetivo y social, en un contexto regional en el que migrar y estudiar se entiendan derechos universales.

\section{Referencias}

Ansaldi, W, Giordano, V. (2016) América Latina. La construcción del orden. Ariel: Buenos Aires.

Bertaux, D. (1997) Los relatos de vida. Perspectiva etnosociológica. Barcelona: Bellaterra.

Brunner, J.J. (2008). El sistema de educación superior en Chile: un enfoque de economía política comparada. Avaliação, 13 (2), 451-486

Cuenca, R. (2015) Democratización del acceso y la precarización del servicio. La masificación universitaria en el Perú, una introducción. Lima: IEP.

Chiroleu, A.; Suasnábar, C.; Rovelli, L. (2012) Política universitaria en la Argentina: revisando viejos legados en busca de nuevos horizontes. Buenos Aires: UNGS.

De Sousa Santos, B. (2006) La universidad popular del siglo XXI. Lima: Universidad Nacional Mayor de San Marcos.

Del Acebo Ibanéz, E. (1996) Sociología del arraigo. Buenos Aires: Claridad.

Díaz, J. (2008) Educación superior en el Perú: tendencias de la demanda y la oferta. En Análisis de programas, procesos y resultados educativos en el Perú: contribuciones empíricas para el debate. Lima: GRADE, 83-129.

Didriksson, A. (2018) De la conciencia crítica a la producción de un conocimiento sustentable y de bien social: entre La Habana (1996) y Cartagena (2008) a Córdoba (2018), el debate sobre la Universidad en América Latina y el Caribe. En Suasnabar, C.; Del Valle, D. Balance y desafíos hacia la CRES 2018. 
Buenos Aires: Petersen, 49-60.

Domenech, E. (2009) Migración y política: el estado Interrogado. Procesos actuales en Argentina y Sudamérica. Córdoba: Editorial UNC.

Ezcurra, A. (2011) Igualdad en educación superior. Un desafío mundial. Buenos Aires: Ediciones UNGS.

Falcón Aybar, M.; Bologna, E. (2013) Migrantes antiguos y recientes: Una perspectiva comparada de la migración peruana a Córdoba, Argentina. Revista Migraciones Internacionales, 7(1), 235-266.

Fernández Lamarra, N. y Costa De Paula, Ma. (Compiladores) (2011). La Democratización De La Educación Superior En América Latina. Limites Y Posibilidades. Sáenz Peña: Eduntref.

Fernández Lamarra, N. (2010) Hacia una nueva agenda de la Educación Superior en América Latina. México: ANUIES.

Gibaudant, A.; Luna, P. (2010) La Docta su verdadero significado. Reconstrucción histórica de la Universidad Nacional de Córdoba. Córdoba: Sarmiento editor.

Giraldo Quintero, R. (2017) Las migraciones colombianas al exterior: Retrospectiva de una realidad que no muta. Opción, 33 (83), 610-642

Greimas, A.; Fontanille, J. (2002) Semiótica de las pasiones. De los estados de cosas a los estados de ánimo. Buenos Aires: Siglo XXI editores.

Guarga, R. (2018) A cien años de la Reforma Universitaria de Córdoba. Hacia un nuevo manifiesto de la educación superior latinoamericana. Caracas: UNESCO-IESAL
C. Córdoba: Universidad Nacional de Córdoba.

Habermas, J. (1999) Teoría de la acción comunicativa. Madrid: Taurus Humanidades.

Jensen, F.; Perret, G. (2011) Migración chilena en Argentina. Entre el exilio político y la migración económica-cultural. En Revista Sociedad y Equidad, (2), 143-162.

Lussault, M. (2015) El hombre espacial. La construcción social del espacio humano. Buenos Aires: Amorrortu

Melella, C. (2014) Migraciones emergentes hacia la Argentina: colombianos y ecuatorianos. Breve panorama y estrategias de inserción cultural. Si Somos americanos, 14(2), 15-46.

Ministerio de Educación, Centro de Estudios, Unidad de Estadísticas (2016). Resumen Estadístico de la Educación 2016. Recuperado de http://datos.mineduc.cl/dashboards/19758/ bases-dedatos-resumen-de-matricula-por-ee/

Ministerio de Educación Nacional de Colombia (2010) Boletín Informativo: Reforma a la Ley 30: Más recursos para la educación superior Educación Superior. Recuperado de https://www.mineducacion.gov.co/1759/arti cles-92779_archivo_pdf_Boletin15.pdf

Moloco, V. (2016) Análisis histórico-demográfico de la inmigración en la Argentina del Centenario al Bicentenario Papeles de población, 22 (89), 201-222.

Mollis, M. (2006) Geopolítica del Saber: Biografías Recientes de las Universidades Latinoamericanas. En Teichler, U. (Ed.). Reformas de los Modelos Educativos de la Educación Superior en Europa, Japón y América Latina: Análisis Comparados 
Derecho a la educación superior en Latinoaméricay migraciones hacia las universidades estatales argentinas

(85-101). Madrid: Miño y Dávila.

Mora Cortés, A. (2016) La seudorrevolución educativa: desigualdades, capitalismo y control en la educación superior en Colombia. Bogotá: Editorial Pontificia Universidad Javeriana.

Mora Toscano, O. (2005) Las políticas educativas en América Latina: un análisis de la educación superior desde la visión de la banca multilateral, Apuntes del Cenes, 25 (40), 249-262.

Nejamkis, L. (2016) Politicas migratorias en Argentina, 1976-2010. De la Doctrina de Seguridad nacional, a la consolidación del derecho humano a la migración. Prometeo: Buenos Aires

Pérez Rasetti, C. (2014) La expansión de la educación universitaria argentina: políticas y actores. Núcleo de estudios e investigaciones en educación superior del Mercosur, 2, 8-32.

Rama, C. (2007) La Tercera Reforma de la Educación Superior en América Latina y el Caribe: masificación, regulaciones e internacionalización. En la UNESCO; IESALC, Informe sobre la educación superior en América Latina y el Caribe 2000-2005. La metamorfosis de la educación superior. Caracas. Recuperado de https://www.oei.es/historico/salactsi/inform
e_educacion_superiorAL2007.pdf

Rodrigues Dias, M.A. (2018) ¿Una nueva reforma de Córdoba? Prioridad a la esperanza y a la utopía contra la opresión y el oscurantismo. En Suasnabar, C.; Del Valle, D. Balance y desafíos hacia la CRES 2018. Buenos Aires: Petersen, 29-48.

Rodríguez, J.; Montoro, L (2013) La educación superior en el Perú: situación actual y perspectivas. Lima, Pontificia Universidad Católica del Perú.

Rodríguez Vignolo, J. (2008) Migración interna de la población joven; el caso de América Latina. En Revista latinoamericana de población, 2 (3), 9-26.

Sayad, A. (2010) La doble ausencia. De las ilusiones del emigrado a los padecimientos del inmigrado. Barcelona: Anthropos

Tedesco, J.C. (2012) Educación y justicia social en América Latina. Buenos Aires: Fondo de Cultura Económica

Terán, O. (2008) Historia de las ideas en Argentina. Diez lecciones iniciales, 1810-1980. Buenos Aires: Siglo XXI

Wright Mills, C. (2003) La promesa. La imaginación sociológica. México: Fondo de Cultura Económica. 


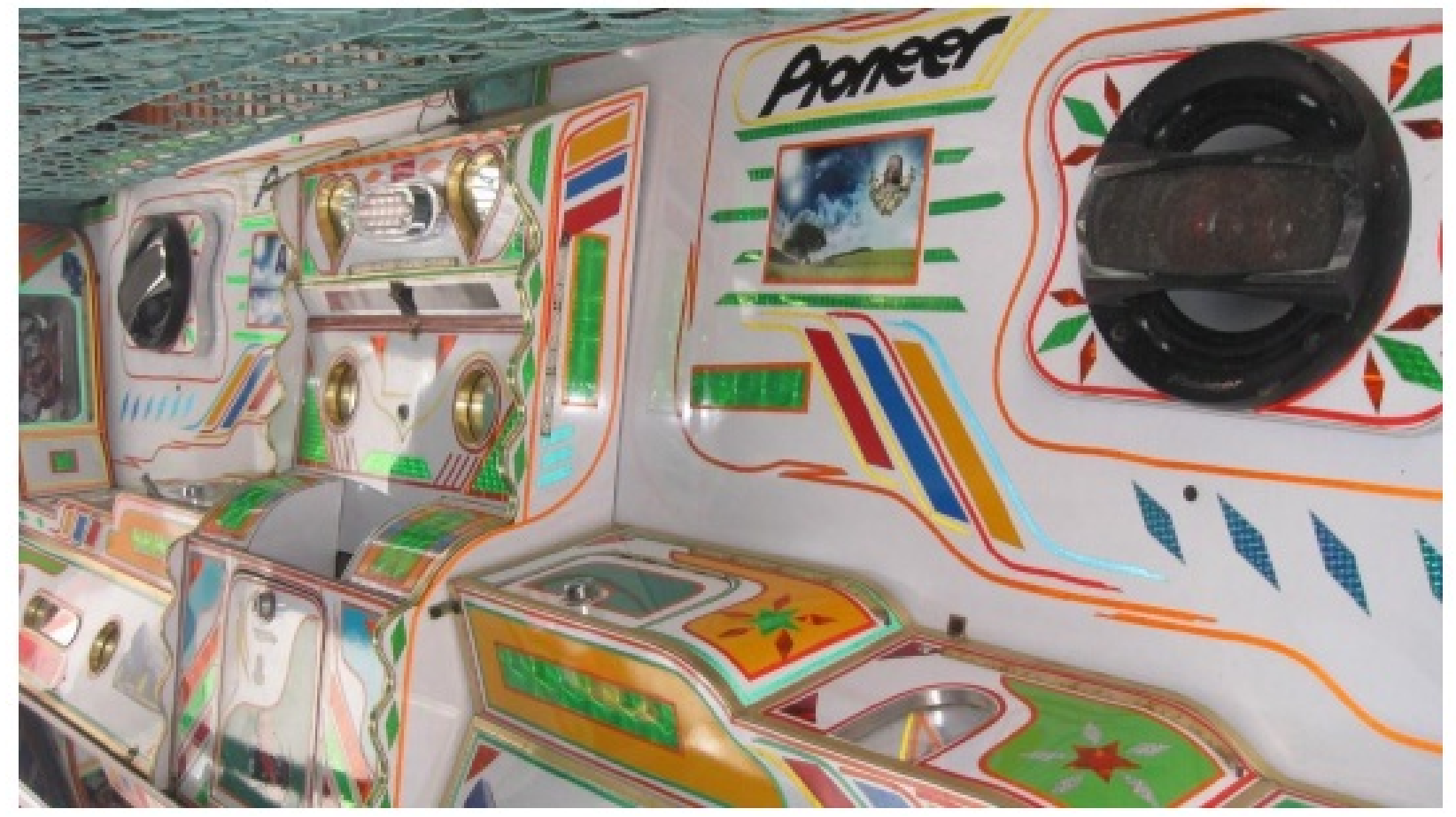

Número de la obra: 83

Título: Chiva "El Lucerito"

Autora: Margarita Chávarro Castro

Lugar: Municipio La Plata, Huila

Fecha de captura: Abril de 2013

Técnica: Fotografía digital

Fuente: Colección Margarita Chávarro Castro 